\title{
Avaliando Traduções
}

\section{Vinicius Martins ${ }^{*}$}

\begin{abstract}
Translation criticism is often made by people not so familiar with Translation Studies and, even in the case of newspaper reviews, based on unclear criteria. This article rehearses an approach to the problem of evaluating translation from four authors: HALLIDAY (2001), HOUSE (1997 and 2001), REISS \& VERMEER (1984) and TOURY (1978), in an effort to indicate in what sense and for what reason critical evaluation of translations, while necessary and, in our view, possible, needs to consider a wider range of criteria to be really useful to the translation reader, beyond simplistic views of the relationship of "fidelity" between source text and target text.
\end{abstract}

Keywords: Translation Studies - Translation criticism - Evaluation parameters Dialect translation.

Resumo: A crítica de tradução é frequentemente feita por pessoas pouco familiarizadas com os Estudos da Tradução e, mesmo no caso das resenhas jornalísticas, a partir de critérios pouco claros. Este artigo ensaia uma abordagem da problemática envolvida na avaliação de traduções a partir de quatro autores: HALLIDAY (2001), HOUSE (1997 e 2001), REISS e VERMEer (1984) e TOURY (1978), num esforço para apontar em que sentido e por que a avaliação crítica de traduções, embora necessária e, de nosso ponto de vista, possível, precisa levar em conta uma maior variedade de critérios para ser de fato útil a um usuário da tradução, indo além de visões simplificadoras da relação de "fidelidade" entre texto-fonte e textometa.

Palavras-chave: Estudos da Tradução - Crítica de tradução - Parâmetros de avaliação - Tradução dialetal.

\footnotetext{
* Mestrando da área de Língua Espanhola e Literaturas Espanhola e Hispano-Americana (FFLCH-USP). Apoio CAPES. Email: martins.vi@ig.com.br.
} 
Martins, Vinicius - Avaliando Traduções

\title{
1 Introdução
}

Em um país como o Brasil, onde a tradução de livros estrangeiros atinge uma marca bastante expressiva no mercado editorial $180 \%$ dos livros são traduzidos, segundo WYLER 2003), é contraditório o tratamento que a imprensa nacional reserva à tradução. Na grande maioria dos casos, o tradutor tem seu nome omitido em resenhas, anúncios e listas de livros mais vendidos. ESTEVES (2002) observa que as resenhas jornalísticas tendem a mencionar a tradução apenas quando esta é considerada de má qualidade. Contudo, em que critérios de avaliação se baseiam os resenhistas para julgar o trabalho do tradutor? Conforme WYLER (2003: 18), a maior parte das críticas feitas às traduções tem como base teorias logocêntricas, atualmente muito questionadas.

\begin{abstract}
Segundo o logocentrismo, o texto de partida seria um objeto definido, congelado, receptáculo de significados estáveis, em geral identificados com as intenções de seu autor. Caberia ao tradutor transportá-lo, fielmente, para o seu próprio texto na língua-receptora. A esta visão contrapõe-se a de que as palavras de uma língua ganham e perdem significados continuamente e que cada tradutor, conforme as influências que recebeu durante a vida, vai recortá-las de um modo muito seu. Em um nível mais teórico, a relação entre o autor e seu tradutor não seria necessariamente marcada pela harmonia e a fidelidade. Muito ao contrário, a tradução seria o lugar da luta pelo poder, que é em última análise a luta pelo poder autoral. (WYLER 2003: 18-19).
\end{abstract}

Mesmo deixando um pouco em suspenso a questão colocada por Wyler e aceitando a possibilidade de uma avaliação crítica baseada nas relações semânticas e formais de uma tradução com seu texto-fonte e centrada na noção de equivalência, delimitar critérios claros para avaliar traduções é uma tarefa difícil. Desde CATFORD (1965), foram vários os estudiosos da tradução (ex.: BAKER 1992; House 1997; ReISS e VermeEr 1984; Halliday 2001; Hatim e MASON 1990) que 
Martins, Vinicius - Avaliando Traduções

explicitaram que há diversos níveis possíveis para considerar a equivalência, já que um texto, visto em seu aspecto de produto linguístico e cultural, tem pelo menos tantos níveis e aspectos quanto os que tem um sistema linguístico (fonético, morfológico, sintático, semântico), uma organização textual (ex.: coesão e coerência), e um acontecimento discursivo (ex.: possui dimensões de contexto, como registro; inserção própria em formações discursivas; fenômenos de intertextualidade). No mínimo, haveria que se perguntar com qual desses níveis e aspectos se espera que o tradutor mantenha equivalência, e por que privilegiar este ou aquele. A história da tradução ainda mostra que o que é considerado uma boa tradução muda com a época e com a sociedade, e nem sempre a equivalência foi o critério central para considerar que uma tradução é boa. Na França dos séculos XVII e XVIII, a tradução ideal seguia um estilo que ficaria conhecido como belles infidèles, em que "os tradutores franceses, a fim de chegar à clareza de expressão e à harmonia de som, muitas vezes faziam acréscimos, alterações e omissões nas suas traduções" (MILTON 1993: 49). 0 principal intuito desse estilo era causar no leitor a impressão semelhante à que 0 original poderia ter causado. Em contrapartida, os escritores alemães dos séculos XVIII e XIX preferiram uma tradução que seguisse mais de perto as "formas morfológicas e sintáticas do original" (ibidem: 50), o que mostra que tampouco a "naturalidade" da tradução foi sempre e em todos os casos um parâmetro universal para aferição de qualidade. Goethe, por exemplo, defendia a proposta de que o texto traduzido ficasse idêntico ao original, "mas ao mesmo tempo conservando-Ihe a estranheza aparente" (ibidem: 56). A. W. Schlegel, Humboldt e Schleiermacher expressaram idéias nesse mesmo sentido (cf. a antologia de VEGA 1994). Schleiermacher, aliás, classificou duas maneiras de traduzir que continuam sendo um paradigma para a tradução literária até o presente século. Dado que há uma distância ineludível entre cultura de origem e cultura de chegada, formula ele, é inevitável que o tradutor precise escolher entre duas atitudes possíveis. Na primeira, o tradutor leva o autor até o leitor, isto é, tenta 
Martins, Vinicius - Avaliando Traduções

produzir nos leitores da língua-meta o efeito mais semelhante possível ao causado pelo original nos leitores da língua-fonte, para isso, é necessária uma transferência generosa dos marcadores culturais da língua-fonte para a cultura e língua da tradução. Na segunda forma, o tradutor leva o leitor até o autor, ou seja, busca transmitir para o texto-meta, à medida do possível, o significado contextual exato do original, mantendo a cultura e as formas estrangeiras do texto-fonte. Schleiermacher insinua uma preferência pelo segundo modo.

TOURY (1978) retoma a discussão sobre essas duas formas de traduzir a partir do conceito de normas. O tradutor poderá traduzir um texto se submetendo às normas que operam no texto-fonte, no que diz respeito ao estilo linguístico e cultura, e desta forma sua tradução privilegiaria a aceitabilidade, ou então poderá se submeter às normas da cultura meta, o que conferiria ao texto maior adequação. Mesmo quanto a privilegiar a aceitabilidade ou a adequação, cada sociedade trabalha com um sistema de normas específicas para a tradução: as normas tradutórias. Portanto, o conceito de boa tradução estará sempre sujeito às normas tradutórias empregadas por uma determinada comunidade cultural em um certo período.

Mesmo diante desse esboço da complexidade de fatores envolvidos na avaliação de traduções, alguns autores dentro dos Estudos da Tradução procuraram estabelecer critérios consistentes, que são bastante úteis para que a avaliação crítica ultrapasse o puro impressionismo, o juízo fragmentário emitido a partir de "erros" pontuais caçados aqui e ali, ou uma simplificação ingênua da noção de equivalência entre texto-fonte e texto-meta.

Pode-se até aspirar a que aqueles que não são profissionais da tradução façam uso desses critérios para os mais variados fins, já que, a partir deles, um resenhista poderia indicar um livro traduzido para seus leitores explicitando as qualidades positivas e/ ou negativas da tradução; um professor encontraria mais facilmente a tradução mais adequada de um livro para seus alunos, levando em conta se ele busca uma adaptação do texto-fonte para que sua turma de 
Martins, Vinicius - Avaliando Traduções

colegiais tenha um primeiro contato com a obra ou se procura uma tradução que se aproxime consideravelmente do texto-fonte para seus estudantes universitários; um grupo de teatro que deseja encenar determinada obra e pode ter suporte para encontrar uma tradução que se adeque mais ao interesse que tem em levar à cena aquela peça.

\section{Parâmetros para avaliação}

Apresentaremos a seguir as considerações de alguns autores acerca de parâmetros para avaliar traduções. Posteriormente, discutiremos a relevância de cada uma das propostas apresentadas, isto é, procuraremos emitir um juízo sobre o grau de eficácia de tais propostas para avaliar criticamente o produto de um ato tradutório.

Para HALlidAY (2001), há uma questão lógica que precede necessariamente qualquer discussão sobre a boa tradução: é preciso, antes de mais nada, que 0 texto seja uma tradução. A questão, que pode parecer óbvia, está longe de ser simples, como já discutimos, porque implica encontrar qual é a relação essencial entre dois textos que levaria a definir um deles como tradução de outro, já que a similitude entre eles poderia acontecer em diversos níveis, mas não simultaneamente entre todos esses níveis.

Conforme HaLlidaY (2001), a relação de semelhança entre dois textos poderia ser considerada pelo menos com relação a estes parâmetros: (1) a organização da linguagem em seu nível fonético, fonológico, léxico-gramático e semântico (stratification); (2) a organização do conteúdo léxico-gramátical e semântico em componentes funcionais, ou seja, as metafunções (metafunctions) ideacional, interpessoal e textual, que dizem respeito, respectivamente, à representação das experiências humanas por meio dos recursos linguísticos, às 
marcas das relações sociais inscritas na língua e à organização do discurso; (3) a organização fonológica e léxico-gramatical numa composição hierárquica (rank). 0 autor reconhece que a prevalência hierárquica entre as equivalências nesses diversos aspectos e dos níveis dentro de cada um dos três itens mudam para cada texto específico e segundo o contexto da tradução, de forma que, por exemplo, numa dada tradução, a equivalência fonética pode chegar a "valer" mais do que a equivalência semântica. Mesmo assim, Halliday aponta que o critério dominante pelo qual costumamos considerar que um texto é tradução de outro que o precede no tempo é a correspondência ideacional e semântica entre eles. Porém, aponta 0 autor, no que se refere à nossa percepção de que uma tradução seja "melhor" do que outras, parecem ser decisivas as correspondências atingidas nas duas outras metafunções: a textual, relativa às características de organização do texto, e a interpessoal, relativa fundamentalmente ao registro.

Elaborado a partir da linguística sistêmico-funcional, assim como a proposta de Halliday, o modelo de HOUSE (1997) baseia sua análise no "contexto de situação", que se apresenta no texto "por meio de uma relação sistemática entre o ambiente social, de um lado, e, do outro, a organização funcional da linguagem" ${ }^{2}$ (HALLIDAY apud HOUSE 2001: 136). As partes administráveis do contexto de situação, ou seja, suas características observáveis, são as "dimensões situacionais" marcadas por escolhas linguísticas, que formam um perfil específico do texto, caracterizando sua função. Por meio desses perfis a análise e a avaliação das traduções é feita. A primeira dimensão é a "dimensão do USUÁRIO da língua", em que se incluem: (1) a origem geográfica do usuário; (2) sua classe social e (3) a época em que o texto foi escrito.

A segunda dimensão é a "dimensão de USO da língua", na qual estão incluídos: (1) "meio", que pode ser "simples" (escrito para ser lido) ou "complexo" (escrito para ser falado, abarcando várias subcategorias do discurso

\footnotetext{
${ }^{2}$ Through a systematic relationship between the social environment on the one hand and the functional organisation of language on the other (Todas as traduções de citações são do autor).
} 
Martins, Vinicius - Avaliando Traduções

oral); (2) "participação", referente ao número de participantes no ato de comunicação e que também pode ser "simples" (monólogo ou diálogo) ou "complexa" (mescla de características do monólogo e do diálogo); (3) "relacionamento social", que diz respeito ao relacionamento entre o emissor e 0 receptor, podendo ser "simétrico" (marcado pela existência de solidariedade ou igualdade) ou "assimétrico" (marcado pela presença de algum tipo de autoridade); (4) "atitude social", referente aos graus de distanciamento ou proximidade social, correspondentes aos níveis de formalidade. Diferencia-se de (3), sobretudo pela gama de classificações fornecidas pela autora (frio ou técnico, formal, consultativo ou informal, casual e íntimo); (5) "área de operação", que se refere à terminologia, estilo e registro de determinado campo profissional e ocupacional empregado no texto (ex.: "a linguagem da propaganda"; "a linguagem da ciência").

No texto traduzido, essas dimensões estão materializadas linguisticamente em escolhas sintáticas, lexicais e textuais. Quando há falha de correspondência (matching) entre as dimensões do texto-fonte e do texto-meta, temos um "erro encoberto" (convert erroneous error). Os casos em que ocorrem faltas de correspondência do significado denotativo entre texto-fonte e texto-meta (omissões, adições e substituições), problemas no manejo das normas gramaticais e no uso da língua-meta são classificados por House como casos de "erro evidente" (overt erroneous error).

O pressuposto de House para propor um modelo de avaliação de qualidade como 0 anterior coincide com 0 de Halliday: se algo não é uma tradução, não é possível dizer que é uma boa tradução. E identificar algo como uma tradução, dentro desse modelo, implica olhar para o texto-fonte, descrever seu perfil a partir desses vários níveis, incluindo as "dimensões do contexto" inscritas na materialidade linguística, e então olhar para a tradução em termos de correspondência de sua organização ou perfil textual-funcional com o do textofonte. As duas abordagens anteriores são, portanto, orientadas ao texto-fonte. 
Martins, Vinicius - Avaliando Traduções

House não ignora as distâncias culturais ineludíveis das quais já falava Schleiermacher. Nesse sentido, coloca-se o problema de como encontrar "correspondências" entre as configurações de dialetos geográficos internas a cada língua. Por exemplo, haveria no alemão, um dialeto geográfico que "correspondesse" às marcas da fala de um irlandês dentro de uma obra de teatro escrita em inglês? Também não desconsidera que há textos profundamente arraigados em sua cultura e época de produção, e que têm seu valor para outras culturas dado justamente por esse interesse "documental", como seria o valor artístico e histórico de um clássico literário ou o interesse histórico que leva o discurso de um importante líder político a ser traduzido para outras línguas, ao mesmo tempo em que há textos cujo motivo da tradução não virá de sua inserção especial na cultura em que foi escrito. Para lidar com essa dificuldade para a avaliação crítica, House retoma os polos propostos por Schleiermacher, defendendo que esses dois tipos diferentes de texto demandarão dois tipos diferentes de tradução e de foco no momento da avaliação crítica.

Os textos que estão sendo traduzidos tendo em vista seu interesse histórico e documental serão abertamente apresentados pelo tradutor ao leitor como traduções (overt translations), e a correspondência entre a tradução e 0 texto-fonte será mais importante nos níveis linguístico-textuais, do registro e do gênero. Nesse caso, a equivalência funcional é ainda possível, mas em outro nível: a tradução permitirá o acesso à função que o original tinha em seu próprio entorno sociocultural e discursivo, como se o leitor da tradução não fosse diretamente abordado como leitor, mas pudesse observar de fora a cena discursiva original, na posição de observador externo (from outside).

No caso de textos que não são fortemente enraizados na língua e culturafonte e não são especificamente formulados para um público-alvo da cultura fonte, a tradução é normalmente motivada por necessidades semelhantes de um público comparável ao do texto-fonte. Nesse caso é que a função do texto-fonte e a função de sua tradução serão também comparáveis. 0 tradutor tenta então 
recriar o evento discursivo, e para isso será legítimo manipular o original nos níveis linguístico-textuais e no nível do registro, valendo-se do que House chama de "filtro cultural", para obter equivalência de gênero e de função individual do texto. 0 resultado pode ser o de uma tradução consideravelmente distante do original, na qual as marcas que permitiriam reconhecê-la como um texto não produzido originalmente na cultura meta são encobertas, relocalizadas na cultura meta (covert translation).

Na avaliação de traduções, House considera essencial adotar diferentes critérios para a tradução "ostensiva" e a tradução "encoberta". Para House, a maior dificuldade que um tradutor enfrenta ao traduzir os textos fortemente arraigados na cultura fonte é encontrar "equivalentes" linguístico-culturais, especialmente nas dimensões do tom (Tenor), com suas marcas da origem temporal, social e geográfica a partir das quais o autor elaborou o texto-fonte. Como faltam estudos contrastivos abrangentes no âmbito etnográfico que fundamentem, por exemplo, o grau de correspondência entre dialetos em termos de prestígio social e status, esse é um ponto em que a avaliação de tradução necessariamente permanecerá mais subjetiva, em certo grau. Por outro lado, no caso da tradução "encoberta", o crítico lida com a dificuldade de avaliar diferenças entre pressupostos culturais e comunicativos entre a produção textual na cultura fonte e na cultura meta, que permitam apreciar a pertinência da aplicação do filtro cultural fundamentada nessas diferenças, distinguindo entre tradução encoberta e adaptação (House usa, respectivamente, os termos covert translation e covert version, p. 142).

ReISS e VERMEER (1984) apontam a finalidade (Skopos) como o princípio dominante da tradução: "o princípio dominante de toda tradução é sua finalidade" (1984: 80); "é mais importante que um translatum (uma translação) atinja um objetivo dado do que o modo determinado em que é realizada" (1984: 84). Para exemplificar o princípio de finalidade, Vermeer formula: 
Martins, Vinicius - Avaliando Traduções

... suponhamos que se queira traduzir o Gênese com a função de texto ritual [...]. É importante reproduzir o texto o mais literalmente possível, seu sentido é secundário. Suponhamos que se queira traduzir a Bíblia com uma função estética. Será mais importante atingir um valor estético, de acordo com as expectativas da cultura-meta (!), do que reproduzir o texto literalmente. Suponhamos que se queira traduzir a Bíblia com a função de texto informativo. O importante será que fique claro o sentido do texto (na medida do possível); neste caso existem os objetivos subordinados: para os teólogos, para os leigos na matéria etc [...] Portanto, não existe $A$ (única forma de realizar uma) tradução de um texto; os texto-meta variam dependendo da finalidade que se pretenda atingir (VERMEER 1984: 84).

A partir da ideia de que o texto-fonte e o texto-meta podem diferir em suas funções, Reiss propõe uma diferenciação entre os conceitos de adequação e equivalência, assim definidos:

Adequação na tradução de um texto (ou elemento textual) de partida se refere à relação existente entre 0 texto final e 0 de partida sempre levando em conta o objetivo (Skopos) que se pretende com o processo de tradução (REISS 1984: 124). ${ }^{3}$

Equivalência expressa a relação entre um texto final e um texto de partida que podem cumprir de igual modo a mesma função comunicativa em suas respectivas culturas. (REISS 1984: 124). ${ }^{4}$

Equivalência é, segundo nossa definição, um tipo especial de adequação, isto é, adequação quando a função entre o texto de partida e o final se mantém constante. (REISS 1984: 125). ${ }^{5}$

De acordo com a ideia de que a tradução não é nem deve ser guiada apenas pela manutenção das características do texto-fonte, 0 avaliador deveria observar prioritariamente se o objetivo pretendido pelo tradutor foi atingido.

\footnotetext{
${ }^{3}$ Adecuación en la traducción de un texto (o elemento textual) de partida se refiere a la relación que existe entre el texto final y el de partida teniendo en cuenta de forma consecuente el objetivo (escopo) que se persigue con el proceso de traducción.

${ }^{4}$ Equivalencia expresa la relación entre un texto final y un texto de partida que pueden cumplir de igual modo la misma función comunicativa en sus respectivas culturas.

${ }^{5}$ Equivalencia es, según nuestra definición, un tipo especial de adecuación, es decir, adecuación cuando la función entre el texto de partida y el final se mantiene constante.
} 
Martins, Vinicius - Avaliando Traduções

Para isso, ReISS e Vermeer (1984: 131-135) introduzem um modelo de fatores relevantes para a tradução no qual incluem: o tradutor, o autor do texto de partida, o tipo de texto, a categoria do texto (informativa, expressiva ou operativa), o contexto situacional (tempo e lugar), o contexto sociocultural e 0 receptor do texto de chegada. A partir da consideração desses fatores, 0 avaliador analisaria se as escolhas feitas pelo tradutor são pertinentes à finalidade que este procura.

A partir de um paradigma também orientado à cultura meta, mas diferente do da Skopostheorie por visar uma abordagem descritiva da tradução, TOURY (1978) afirma que "são as normas que determinam (tipo e importância da) equivalência manifestada por traduções reais" (1978: 204) e que as normas tradutórias são "dependentes da posição ocupada pela tradução - tanto a atividade como seus produtos - na cultura meta" (1978: 204). A perspectiva de Toury chama a atenção para o fato de que a avaliação da qualidade de tradução passa necessariamente pelo crivo da comunidade à qual ela é destinada, e aponta para a centralidade da noção de "normas" nesse fenômeno.

Toury descreve as restrições socioculturais como uma escala na qual regras e idiossincrasias são colocadas em cada um dos extremos, enquanto as normas, classificadas como fatores intersubjetivos, se posicionam entre esses extremos. As normas mais relevantes são como as regras, enquanto que as mais irrelevantes são quase idiossincráticas. Contudo, as normas não possuem uma posição fixa na escala, mas mudam com o tempo, portanto, uma norma pode se tornar uma regra ou uma idiossincrasia, da mesma maneira que uma regra pode se tornar uma norma e assim por diante.

A dificuldade encontrada em qualquer tentativa de explicar as normas tradutórias está em sua especificidade sociocultural e em sua instabilidade através do tempo. Tal instabilidade ocasiona o surgimento de três tipos de norma em dada comunidade: 
Martins, Vinicius - Avaliando Traduções

Aquelas que dominam o centro do sistema e, portanto, coordenam o comportamento tradutório do que é conhecido como a vertente principal, juntamente com o conjunto de normas remanescentes e os rudimentos das novas, pairando na periferia. Por essa razão é possível falar - e não pejorativamente - de estar "em voga", ser "ultrapassado" ou ser "progressista" em tradução (ou em qualquer parte dela) assim como em qualquer outro domínio comportamental (TOURY 1978: 205) ${ }^{6}$.

Segundo o autor, existem duas fontes principais para a reconstrução descritiva das normas tradutórias: a textual, referente aos próprios textos traduzidos, e a extratextual, que diz respeito a formulações críticas e teóricas feitas por qualquer profissional que trabalhe direta ou indiretamente no âmbito da tradução. Finalmente, Toury categoriza a aprovação ou desaprovação entre os membros de um grupo social, de acordo com normas sobre uma série de comportamentos de um certo tipo, da seguinte maneira:

a. Normas básicas (primárias), mais ou menos obrigatórias para todas instâncias de um determinado comportamento (e portanto seu mínimo denominador comum).

b. Normas secundárias, ou tendências, determinação do comportamento favorável. Podem ser predominantes em certas partes do grupo. Consequentemente comuns o bastante, mas não obrigatórias, do ponto de vista do grupo como um todo.

C. Comportamento tolerado (permitido). (TOURY 1978: 208). ${ }^{7}$

Caberá aos membros de determinada sociedade decidir se o texto-meta corresponde às regras e normas estabelecidas e a partir de então classificar a

\footnotetext{
${ }^{6}$ The ones that dominate the centre of the system, and hence direct translational behaviour of the so-called mainstream, alongside the remnants of previous sets of norms and the rudiments of new ones, hovering in the periphery. This is why it is possible to speak - and not derogatorily - of being "trendy", "old-fashioned" or "progressive" in translation (or in any single section thereof) as it is in any other behavioural domain.

${ }^{7}$ a. Basic (primary) norms, more or less mandatory for all instances of a certain behaviour (and hence their minimal common denominator).

b. Secondary norms, or tendencies, determining favourable behaviour. May be predominant in certain parts of the group. Therefore common enough, but not mandatory, from the point of view of the group as a whole.
}

c. Tolerated (permitted) behaviour 
tradução como inaceitável, tolerada ou permitida. As formulações de Toury não têm em vista propor critérios para avaliação crítica de tradução. Como observamos, visam explicar fenômenos, e têm evidente valor como hipótese explicativa para os mecanismos que levam à oscilação do que foi considerado uma boa tradução ao longo da história, e dos métodos que prevaleceram para traduzir em certos grupos, certas épocas, certos países etc. No entanto, também nos valeremos dela para refletir sobre a avaliação crítica de traduções.

\section{Aplicando as propostas}

Para estimar a utilidade dos conceitos e modelos apresentados para fins de avaliação, submeteremos uma tradução a análise lançando mão de cada um deles, assim, poderemos discutir, a partir de um estudo concreto, a aplicabilidade específica de cada um.

A tradução escolhida para análise é um trecho do romance regionalista Don Segundo Sombra (1926) do escritor argentino Ricardo Güiraldes, traduzido ao português por Augusto Meyer (1997). Escolhemos um trecho que acreditamos ser bem característico da obra e onde os problemas encontrados na tradução desse tipo de texto se mostram bastante evidentes. A peculiaridade da obra analisada é o emprego de uma variedade de marcadores para representar a linguagem gauchesca, como o uso do voseo, arcaísmos, a representação gráfica do seseo e do yeísmo, contrações de para, por e de vogais, mudanças e perdas vocálicas e consonantais, próteses, metáteses, troca de acento (tonicidade) e adição de $n$ em algumas formas verbais. Pensamos que uma boa tradução encontraria alguma maneira de representar, na língua-meta, os efeitos de tais características, pois ao não fazê-lo o tradutor estaria privando seu leitor de informações acerca da personagem, do espaço e até mesmo do tempo, informações essas que são 
Martins, Vinicius - Avaliando Traduções

muitas vezes essenciais para a compreensão global de uma obra literária. Em outras palavras, a boa tradução necessita preservar o significado (meaning) do texto-fonte e, para tal, é preciso encontrar na língua e cultura-meta os aspectos semânticos e também pragmáticos do significado. "Uma tradução adequada é, portanto, aquela equivalente pragmática e semanticamente" ${ }^{8}$ (HOUSE 2001: 136).

Não obstante, já a partir de House, reconhecemos os problemas que a tentativa de representação de uma variante dialetal podem ocasionar no textometa. HATIM e MASON (1990) citam um exemplo de tradução dialetal diatópica controversa, ocorrido na Grã Bretanha, em que foi utilizado o dialeto escocês para representar na língua inglesa a fala de camponeses russos, em uma teledramaturgia estrangeira. Tal fato parecia insinuar que o dialeto escocês estava associado às classes sociais mais baixas, sendo, portanto, uma variante de pouco prestígio, e provocou protesto de parte de escoceses. Embora o exemplo faça referência à dublagem, tal fato também poderia ocorrer em casos de tradução literária. Os autores fazem o seguinte alerta:

O conhecimento da variante geográfica, e das implicações ideológicas e políticas que ela pode suscitar, é essencial para tradutores e intérpretes. O sotaque, por exemplo, é um dos traços mais perceptíveis da variante geográfica e, frequentemente, uma fonte de problemas. (...) Da mesma forma que produtores e diretores, os tradutores devem estar em constante alerta às implicações sociais de suas decisões. A representação no TF de um determinado dialeto gera um problema inescapável: que dialeto da LM será usado? (HATIM e MASON 1990: 40) ${ }^{9}$

Os tradutores também poderiam facilmente incorrer em uma representação preconceituosa e caricata, reduzindo a variante dialetal a palavras

\footnotetext{
${ }^{8} \mathrm{An}$ adequate translation is thus a pragmatically and semantically equivalent one.

${ }^{9} \mathrm{An}$ awareness of geographical variation, and of the ideological and political implications that it may have, is therefore essential for translators and interpreters. Accent, for example, is one of the more recognisable features of geographical variation and is often a source of problems. (...) Like producers and directors, translators have to be constantly alert to the social implications of their decisions. The representation in a ST of a particular dialect creates an inescapable problem: which TL dialect to use?
} 
Martins, Vinicius - Avaliando Traduções

e expressões estereotipadas, ou ainda, mesclar uma série de dialetos. Todas essas opções, à semelhança do dialeto padrão, descaracterizariam as personagens e, portanto, o esforço de encontrar uma representação dialetal teria sido em vão.

Segue abaixo o trecho extraído de Don Segundo Sombra e sua tradução:

Capítulo VII

- Stan muy amontonados pa contarlos -reía Pedro Barrales.

- No, si está eligiendo la res pa ponerle el lazo -contestábale Horacio.

- ¡Mozo! -gritó Valerio-, si se me hace que ya lo veo atravesao sobre el recao y con las nalgas p'arriba pa que lah'alivee el fresco.

- Me están boliando parao -retruqué-; dej enmé siquiera que corra un poco.

La conversación se hacía a gritos, mientras, uno de aquí, otro de allá, menudeábamos porrazos a los rezagados que marcaban un intento de escapar para la querencia.

- Vez pasada -contó Pedro- cuando juimos de viaje pa Las Heras, ¿te acordah', Horacio?, Io Ilevábamos de bisoño a Venero Luna. Hubieran visto la bulla que metía este cristiano. Puro floriarse entre el animalaje. Tenía una garganta como trompa'e línea y déle p'acá, déle p'allá, les gritaba: "Ajuera guay, aj uera guay". Pero, cuando llevábamos cinco días de arreo, al hombre se le jueron bajando los humos. A la llegada, ya casi no se movía. "Era ey, era ey", decía como si estuviese rezando, y estaba de flaco y sumido que me daban ganas de atarlo a los tientos. (p. 43-44).

(GÜIRALDES, Ricardo. Don Segundo Sombra; edição crítica, Paul Verdevoye, coord. Madrid; Paris; Cidade do México; Buenos Aires; São Paulo; Rio de J aneiro;

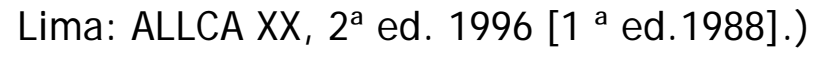


Martins, Vinicius - Avaliando Traduções

Capítulo VII

- Estão muito amontoados pra contares - riu Pedro Barrales.

- Quê, se está escolhendo o animal pra Ihe pôr o laço - respondeu Horácio.

- Moço - gritou Valério -, me parece que já Ihe vejo atravessado sobre os arreios e de bunda pra cima, pra aliviar-se ao fresco!

- Me estão boleando parado - retruquei -, deixem-me ao menos que corra um pouco.

A conversação fazia-se a gritos, enquanto um daqui, outro de lá, amiudava pancadas nos atrasados que mostravam intenção de fugir para a querência.

- A vez passada - contou Pedro -, quando fomos de viagem pra Las Heras, lembras-te, Horácio?, levávamos de novato a Veneno Luna. Só vendo o barulho que fazia aquele cristão. Puro florear-se no meio da animalada. Tinha uma garganta de trombone de banda. E dê-le pra cá, e dê-le pra lá, aos gritos: "Fora, boi; fora, boi". Mas, quando já levávamos cinco dias de tropeada, Ihe foi baixando a crista. Na chegada já quase nem se mexia: "ora 'oi, ora 'oi", dizia como rezando; e, de tão magro e sumido, me dava ganas de atá-lo nos tentos. (p. 58).

(GüIRALDES, Ricardo. Dom Segundo Sombra. Trad. port. de Augusto Meyer. Porto Alegre: L\&PM, 1997.)

A tradução de Meyer pode ser caracterizada como próxima da linguagem padrão, visto que o tradutor não buscou nenhum tipo de equivalência ou compensação ${ }^{10}$ para as palavras que aparecem marcadas pelo dialeto no textofonte, stan por están, juimos por huimos, dentre outros. Todas elas são

${ }^{10}$ A compensação é utilizada na tradução quando há a impossibilidade de se encontrar uma equivalência de efeito para uma determinada palavra do texto-fonte e o tradutor busca tal efeito em outra palavra do texto-meta. 
Martins, Vinicius - Avaliando Traduções

traduzidas por um correspondente na língua padrão em português (estão e fomos). Ainda poderíamos afirmar que Meyer fez uso da norma culta, dado o uso da ênclise, que caracteriza esse tipo de linguagem no português brasileiro. Tal feito poderia gerar uma visão deturpada das personagens para o leitor da tradução.

As considerações de Toury levaria a considerar que os membros de uma mesma comunidade cultural poderiam divergir quanto à qualidade da tradução, pelo menos no sentido de que haveria aqueles favoráveis a uma tradução mais próxima do texto-fonte (adequação) e os favoráveis a um maior ajuste à cultura meta (aceitabilidade). Naquele caso, a tradução não seria tão diferente da realizada por Augusto Meyer, já que nesta se mantêm as referências ao tipo de pecuária e às localidades da cultura-fonte:

- Vez pasada - contó Pedro -, cuando juimos de viaje pa Las Heras, ¿te acordáh', Horacio?, lo llevábamos de bisoño a Venero Luna. Hubieran visto la bulla que metía este cristiano. Puro floriarse entre el animalaje. Tenía una garganta como trompa'e línea y déle p'acá, déle p'allá, les gritaba: "Ajuera guay, aj uera guay". (...)

- A vez passada - contou Pedro -, quando fomos de viagem pra Las Heras, lembras-te, Horácio?, levávamos de novato a Venero Luna. Só vendo o barulho que fazia aquele cristão. Puro florear-se no meio da animalada. Tinha uma garganta de trombone de banda. E dê-le pra cá, e dê-le pra lá, aos gritos: "Fora, boi; fora, boi". (...)

Em se tratando de uma tradução que visasse a aceitabilidade, seria necessário transpor tais referências para uma realidade mais próxima da cultura- 
Martins, Vinicius - Avaliando Traduções

meta. Suponhamos que na cultura para a qual o texto está sendo traduzido, os bovinos não façam parte da pecuária e que, em vez deles, a criação de javalis seja mais comum. Neste caso, uma tradução possível seria a seguinte:

- A vez passada - contou Pedro -, quando fomos de viagem pra Pouso Alegre, lembras-te, Horácio?, levávamos de novato a Venero Luna. Só vendo o barulho que fazia aquele cristão. Puro florear-se no meio da animalada. Tinha uma garganta de trombone de banda. E dê-le pra cá, e dê-le pra lá, aos gritos: "Fora, leitão; fora, leitão". (...)

Nesta tradução mais próxima da cultura-meta, a referência ao departamento argentino de Las Heras é substituída por alguma localidade que cumprisse a mesma função no romance, que, no caso em particular, é a de simplesmente expressar uma distância considerável da região onde habitam as personagens, visto que eles levaram cinco dias de viagem para chegar ao local. 0 animal do texto-fonte também é substituído por um mais comum à cultura-meta. Assim, entre os membros da comunidade que tivessem a aceitabilidade como critério principal de avaliação, este último exemplo iria mais de encontro ao que esta sociedade considera uma boa tradução.

Contudo, a aplicação dos conceitos de Toury não nos permitiria ir muito além de qualificar a tradução como em voga, ultrapassada ou progressista. A tradução feita por Augusto Meyer poderia ocupar a primeira classificação, se pensarmos que a maioria das traduções de obras que contém algum tipo de dialeto lida com as marcas dialetais neutralizando-as num dialeto padrão, ou ainda, poderia ser considerada ultrapassada, posto que nas últimas décadas emergiram vários trabalhos considerando a importância da tradução dialetal e também reconhecendo que o leitor de obras regionalistas percebe a presença de dialetos como uma das marcas características do gênero. 
Martins, Vinicius - Avaliando Traduções

A proposta de Halliday, pela sua falta de detalhamento quanto a possíveis aplicações concretas, também deixa espaço aberto a várias interpretações. Por um lado, poder-se-ia afirmar que, no tipo de tradução levada a cabo, a equivalência semântica deveria valer mais do que a equivalência lexical e, se assim fosse, teríamos uma tradução de boa qualidade. Por outro lado, ao se afirmar o contrário, a tradução pecaria pela falta de equivalência com o aspecto artístico-formal do texto-fonte. Portanto, o modelo de Halliday, ainda que pudesse ser empregado na avaliação, parece carecer de uma maior exatidão para ser operacionalizado.

Para aplicar à avaliação crítica desta tradução as propostas de Reiss \& Vermeer é necessário primeiramente destacar a finalidade do tradutor. Meyer não escreveu nenhum prefácio esclarecendo suas escolhas, mas a partir de seu trabalho podemos inferir que ele não pretendia levar em conta as marcas do dialeto gaucho presentes no texto-fonte. A partir de então, o modelo entra em contradição, pois a escolha / finalidade do tradutor compromete a tradução nos fatores (1) tipo de texto, já que as convenções literárias que fazem a obra original inserir-se no gênero regionalista não foram consideradas pela tradução, pode-se até falar em desvio, se pensarmos que foi utilizada uma linguagem muito próxima da norma culta (como o uso da ênclise); (2) categoria, porque a organização artística não foi mantida, e no âmbito do (3) receptor do texto final, devido à privação de informações no que tange às personagens, expressivamente inferior em relação aos leitores do texto-fonte.

No entanto, se pensarmos na possibilidade de que fazia parte do intuito do tradutor ou da política editorial que o texto fosse traduzido para uma linguagem culta ou, ao menos, que respeitasse as normas gramaticais da língua padrão, 0 texto-meta teria cumprido sua finalidade. MILTON (2002) expõe o caso do Clube do Livro, fundado no Brasil nos anos 1940, que alcançou um número bastante expressivo de vendas e vigorou até 1989. Com um acervo formado por obras clássicas, nacionais e estrangeiras, o Clube tinha como um de seus principais 
Martins, Vinicius - Avaliando Traduções

objetivos a difusão do livro e da cultura entre as classes com pouco poder aquisitivo. Tal missão se mostrava no discurso dos editores e nas traduções que rechaçavam ou censuravam os hábitos das personagens tidos como pouco saudáveis ou morais. A linguagem considerada chula ou "errada", como era o caso da representação de variantes dialetais, também não foi poupada, sendo traduzida para a variante padrão do português. Nesse caso, podemos afirmar que, apesar das diferenças de interpretação que podem surgir entre os leitores do texto-fonte e do texto-meta devido às omissões e modificações efetuadas na tradução, a finalidade foi respeitada.

Afinal, o que deveremos considerar na avaliação crítica? A finalidade do tradutor ou as consequências que seguir certas finalidades têm sobre a tradução como representação do texto-fonte? Conforme REISS e VERMEER (1984: 119), a tradução de Meyer poderia ser considerada de boa qualidade porque seguiu seu objetivo?

(...) se o tradutor ou seu cliente atribuem à tradução funções comunicativas diferentes das do texto original, já não haverá entre ambos os textos uma relação de "igualdade de valor", visto que só se buscará e encontrará correspondências para dimensões parciais do texto de partida na língua final. Segundo este objetivo, em uma tradução deste tipo falaremos de adequação = conformidade da escolha de signos linguísticos na língua final com relação à dimensão escolhida do texto de partida. Esse será o critério que serve de fio condutor no processo de tradução (REISS e VERMEER 1984: 119). ${ }^{11}$

Aceitaríamos o crivo dos autores se estivesse claro para o público-alvo que a tradução não segue uma equivalência, mas sim uma adequação com relação ao texto-fonte. No entanto, a discrepância no caso em análise não chega a ser tão

\footnotetext{
${ }^{11}$ (...) si el traductor o su cliente le asignan a la traducción funciones comunicativas diferentes de las del texto original, ambos textos ya no mantendrán una relación de "igualdad de valor", dado que sólo se buscarán y encontrarán correspondencias para dimensiones parciales del texto de partida en la lengua final. De acuerdo con este objetivo, en una traducción de este tipo hablaremos de adecuación = conformidad de la elección de signos lingüísticos en la lengua final con respecto a la dimensión escogida del texto de partida. Este será el criterio que sirva de hilo conductor en el proceso de traslación.
} 
Martins, Vinicius - Avaliando Traduções

grande a ponto de se admitir uma adequação, nem tão insignificante para ser tratada como equivalência. Percebe-se uma incapacidade do modelo em prever esse tipo de situação. Essa falta indica que a proposta pareceria simplificar a questão da finalidade, quanto se trata de considerar certas especificidades tradutórias, como a tradução dialetal.

Fazendo uso do modelo de House - que abarca variantes dialetais -, percebemos que a tradução não respeita a "dimensão do usuário da língua", por desconsiderar a origem geográfica e classe social do(s) usuário(s), caracterizando, pois, um "erro encoberto". A gama de especificidades desse modelo permite ao avaliador não apenas verificar a qualidade da tradução, mas especificar com mais precisão onde estão aqueles pontos que considerou problemáticos. Nesse sentido, nos parece especialmente útil também para considerar com criteriosidade a adequação de diferentes traduções a diferentes finalidades, recomendar uma e não outra para determinado interesse específico de um leitor, descrever com maior precisão o tipo de norma tradutória que certo tradutor ou época privilegiaram ao realizar suas traduções.

\section{Considerações Finais}

Confrontando as propostas apresentadas, percebemos que Toury não se apoia em categorias linguísticas e textuais, porém apresenta uma proposta explicativa que permitiria prever como determinada tradução seria recebida por uma comunidade, a partir da descrição de como operam traduções concretas e sua recepção, da configuração das normas tradutórias por trás de escolhas de formas de traduzir, além de permitir compreender o que de fato aconteceu para que variassem os critérios de qualidade ao longo da história da tradução. 
Martins, Vinicius - Avaliando Traduções

Apesar de se apoiar em características linguísticas, os parâmetros de Halliday estão ainda mais arraigados no texto-fonte do que o modelo de House, e isso parece comprometer a análise avaliativa em certos níveis. Parece sensato concordar com Halliday em que toda avaliação de tradução deve considerar 0 texto-fonte, afinal, como o próprio autor coloca, um texto "traduzido" que não busca uma equivalência com seu texto-fonte, não pode ser qualificado como uma tradução. Contudo, Halliday deixa ainda em aberto o problema da atribuição de valor hierárquico às várias relações de equivalência que pode haver entre os dois textos envolvidos no ato tradutório, ou seja, a forma de resolver a seguinte questão: diante da impossibilidade de equivalência em todos os níveis, o que poderia guiar o avaliador para estimar aquele nível que mais se destaca em termos linguísticos, formais e funcionais, e que portanto deveria prevalecer em cada caso? Ainda assim, muitas das observações do autor podem ser utilizadas para definir parâmetros de qualidade.

As propostas de Reiss \& Vermeer e House detalham importantes fatores de análise de qualidade que parecem não estar explicitados na proposta de Halliday. Mas é o modelo de House o que apresenta maior especificidade e permite operacionalizar os vários vetores de equivalência de que fala Halliday, levando ainda em conta importantes aspectos da variação de função e parâmetros extratextuais propostos também por Reiss \& Vermeer. O modelo de House, em um primeiro momento, permite descrever com precisão a presença e ausência de matching. A partir disso, é possível julgar se os mismatching se justificam pela finalidade (tão cara ao modelo funcional de Reiss \& Vermeer), posto que uma nova função foi agregada. Finalmente, busca-se explicitamente, na proposta de House, que a análise feita a partir de uma série de critérios correlacionados embase a emissão de um juízo de valor.

Cabe aqui uma ressalva, o modelo de avaliação de House estabelece critérios de qualidade formulados a partir da relação entre os textos fonte e meta e/ ou da finalidade do tradutor, contudo também é necessário respeitar o 
que procura aquele que lê a tradução, e nesse sentido é a proposta de Reiss \& Vermeer a que dá maior apoio a uma crítica de tradução que pretenda orientar a escolha de uma ou outra tradução entre várias opções existentes. Para um leitor que busca saber apenas o conteúdo (o enredo) de Don Segundo Sombra ou da Odisseia, e que pudesse sentir como "truncado" o texto marcado pelas variantes dialetais do primeiro, ou pela rebuscada forma poética do segundo, poderia ser considerada "melhor" uma tradução em dialeto padrão do livro de Güiraldes e outra em prosa da obra de Homero. Para encontrar uma tradução de determinada forma (em verso ou prosa, dialeto padrão ou regional, estilo mais acadêmico ou popular), ter em conta de forma integrada as considerações dos autores apresentados neste artigo seria especialmente útil, visto que nos habilita a descrever e caracterizar a tradução como deste ou daquele tipo. A diferença é que, nesse caso, sua função não seria mais a de definir a tradução como de boa ou má qualidade, mas sim se ela atende em maior ou menor grau ao que o leitor procura. Essa diferenciação não nos parece irrelevante: vale a pena explicitá-la numa avaliação crítica.

Por fim, como HOUSE aponta, em nossa avaliação sempre haverá um certo grau de julgamento subjetivo, isto é, baseado em nosso gosto pessoal, contudo, uma apreciação contundente também deve considerar que a avaliação pode ser feita a partir de parâmetros analíticos concretos e explicitáveis:

Ambos componentes, o linguístico e o valorativo estão, obviamente, implícitos na avaliação de tradução, mas não devem ser misturados, nem o componente avaliativo deve ser utilizado isoladamente do componente lingüístico (HOUSE 2001: 156). ${ }^{12}$

\footnotetext{
12 Both components, the linguistic and the judgemental are, of course, implicit in translation evaluation, but they should not be mixed up, nor should the evaluative component be used in isolation from the linguistic component.
} 
Martins, Vinicius - Avaliando Traduções

\section{Agradecimento}

Agradeço a leitura e sugestões de Heloísa Pezza Cintrão.

\section{Referências Bibliográficas}

BAKER, M. In Other Words: A Coursebook on Translation. London and New Yord: Routledge, 1992.

CATFORD, J. C. A Linguistic Theory of Translation: An Essay in Applied Linguistics. London: Oxford University Press, 1965.

ESTEVES, L. R. "Quando a resenha não critica: um silêncio não inocente". Crop, São Paulo, no 8, 2002: 333-337.

HallidAY, M. A. K. "Towards a theory of good translation". In: STEINER, E.; YALLOP, C.(eds.). Exploring translation and multilingual text production: beyond content. Berlin and New York: Mouton de Gruyter,2001: 13-18.

HATIM, B.; MASON, I. Discourse and the translator. London and New York: Longman, 1990.

HousE, J. Translation quality assessment - A model revisited. Tübingen: Narr, 1997.

"How do we know when a translation is good? In: Steiner, Erich; Yallop, Colin (eds.). Exploring translation and multilingual text production: beyond content. Berlin and New York: Mouton de Gruyter, 2001: 127-160.

Milton, J .0 poder da tradução. São Paulo: Ars Poética, 1993.

. O Clube do Livro e a tradução. Bauru, SP: EDUSC, 2002.

ReISS, Katharina; Vermeer, Hans Josef ( 1 a ed. original em alemão 1984). Fundamentos para una teoria funcional de la traducción. Trad. Sandra García Reina; Celia Martín de León; Heidrun Witte. Madrid: Akal, 1996.

TOURY, Gideon (1978). "The nature and role of norms in traslation". In: VENUTI, Lawrence; BAKER, M. (orgs.). The translation studies reader. London: Routledge, 2000: 198-211.

VegA, M. A. (ed.). Textos clásicos de teoría de la traducción. Madrid: Cátedra, 1994.

WYLER, L. Línguas, poetas e bacharéis: uma crônica da tradução no Brasil. Rio de J aneiro: Rocco, 2003. 